\section{Is it important to create a PAGES early-career researchers working group? What should be its remit?}

Xavier Benito ${ }^{1}$ and Stella Alexandroff ${ }^{2}$

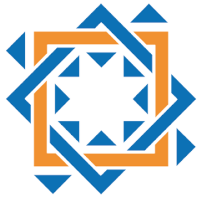

PAGES Morillo de Tou 2017

3rd Young Scientists Meeting

Global Challenges for our Common Future

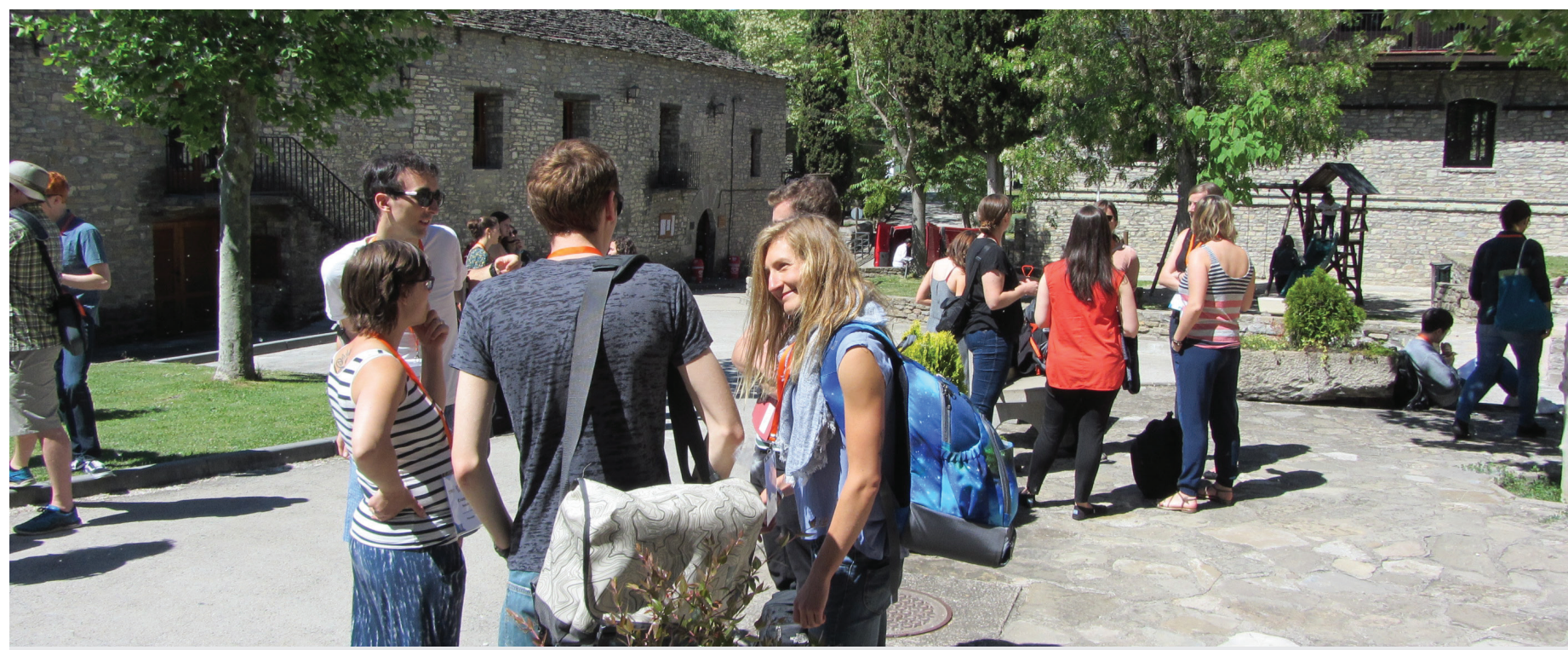

Eighty international participants attended the YSM in Morillo de Tou, providing a great opportunity to network and discuss research.

What are the benefits for young paleoscientists in creating an early-career researchers working group within the framework of PAGES? This key question for the next generation of researchers was discussed during the breakout sessions at PAGES 3rd Young Scientists Meeting held in Morillo de Tou, Spain, in May 2017.

The goal of such a working group would be to favor cohesion among early-career researchers. This can be achieved through different tools and activities:

\section{Platform}

Building a platform for exchange on hard and soft researcher skills is viewed as extremely valuable. It would strengthen collaborations among early-career researchers, promote new science projects and enable early-career researchers to exchange and gain useful knowledge for their future careers. In this context, there is a strong desire to propose workshops and webinars to learn and expand skills, such as database management, specific software, new methodologies, and communication (e.g. practicing talks or how to present a poster). To start with, a skill database of the members' research backgrounds has been developed to enhance online networking within the early-career community.

\section{Communication}

Besides public outreach and science com munication, sharing information was also identified as of paramount importance for early-career researchers. In a very competitive post-PhD world, it is essential for early-career scientists to keep themselves updated about research jobs and funding opportunities. PAGES is a bottom-up international organization consisting of numerous working groups. Although early-career researchers are already actively involved in many PAGES working groups, creating a dedicated early-career researchers working group would potentially increase their visibility and offer a new set of opportunities.

\section{Collaborative projects}

One of the objectives of PAGES working groups is to address big science questions that cannot be answered by single research teams. In this context, there is huge potential for early-career researchers to initiate collaborative projects, since they are usually deeply involved in their own research (e.g. dissertations). Therefore, they can provide new, fresh ideas and scientific hypotheses, although, being strongly focused, they need to develop collaboration to tackle major scientific questions.

\section{Networking}

Many early-career researchers leave the academic sphere for alternative career paths. A dedicated PAGES working group could develop a long-term network with them, to provide mentors outside academia, to identify valuable jobs other than professorships or to liaise with potential stakeholders.
An ECR working group may also act as a link between their own centers/universities and regional and global associations to organize conferences and meetings on PAGES-related topics.

Therefore, an early-career researchers working group is in development. The steering committee, with ten members (five PhD students and six postdocs) from six different countries, is currently working on a formal proposal to create a new working group that addresses all the remits mentioned above and investigates how it can contribute to filling research gaps in PAGES sub-disciplines in the long term.

Early-career researchers in past global changes are very welcome to join. Email us (pages.ecr@gmail.com) or join our online forum (https://groups.google.com/ forum/\#!forum/pages-early-career-scientists) for more details on how to be involved.

\section{AFFILIATIONS}

'Department of Earth and Atmospheric Sciences, University of Nebraska-Lincoln, USA

'School of Ocean Sciences, Bangor University Wales, UK

\section{CONTACT}

Xavier Benito: xbenitogranell2@unl.edu 